\title{
AS POLÍTICAS KEYNESIANAS E A GARANTIA DO PLENO EMPREGO: UM ENSAIO TEÓRICO
}

\author{
Raimundo Nonato Lima Filho ${ }^{1}$ \\ Francisco Marton Gleuson Pinheiro ${ }^{2}$ \\ Romilson do Carmo Moreira ${ }^{3}$
}

\section{Resumo}

Uma vez que a economia atua em um nível de emprego abaixo do pleno emprego, surge então uma estrutura interna do mercado que ajusta e elimina essa lacuna. Em contrapartida, se essa oferta for superior à necessidade de trabalho, a remuneração líquida de mercado vai estar acima de seu ponto de equilíbrio, ou seja, sobrecarregando os mecanismos econômicos que eliminam algum excesso no mercado de trabalho. De tal modo, em um cenário de desemprego, o grande número de trabalhadores disponíveis no mercado em relação à oferta de vagas promove uma diminuição do salário real de mercado, uma vez que a concorrência e o excesso de oferta de mão de obra promovem este panorama. A redução do salário real de mercado é um evento que ocorre permanentemente até que acabe o excesso de mão de obra disponível. Nesse momento, o mercado de trabalho torna-se equilibrado até atingir o pleno emprego em uma economia. Este artigo, portanto, tem como objetivo apresentar uma discussão teórica baseada na Administração Política sobre as contribuições das Políticas Keynesianas para a garantia do pleno emprego. Nesta pesquisa concluiu-se que a intervenção do governo é necessária para atingir e manter o pleno emprego, além de demonstrar o potencial das políticas econômicas nesse contexto. Sendo assim, entende-se que o estudo contribui para o referencial teórico sobre esta temática.

Palavras-chave: Economia; Pleno Emprego; Políticas Keynesianas.

\begin{abstract}
Once the economy operates at a level of employment below full employment, then comes an internal market structure that responds and eliminates the gap. However, if this offer is higher than the need for labor, the net market return will be above its equilibrium point, in other words, overloading the economic mechanisms that eliminate some excess in the labor market. So, in a scenario of unemployment, the large number of workers available in the market in relation to the number of vacancies promotes a decrease in real wages in the market, once the competition and oversupply of manpower they promote this panorama. The reduction in the real market wage is an event that occurs permanently until it runs out excess labor available. Right now, the job market becomes balanced to achieve full employment in an economy. This article therefore aims to present a theoretical discussion based on contributions Policy Administration Keynesian Policies for ensuring full employment. In this research it was concluded that government intervention is needed to achieve and maintain full employment, as well as demonstrating the potential of economic policies in this context. Thus, it is understood that the study contributes to the theoretical reference on this issue.
\end{abstract}

Keywords: Economy; Full Employment; Keynesian Policies.

\footnotetext{
${ }^{1}$ Doutor em Administração (UFBA). Professor da Universidade do Estado da Bahia (UNEB). E-mail: rnlfilho@gmail.com

${ }^{2}$ Mestre em Contabilidade (UFBA). Professor da Universidade do Estado da Bahia (UNEB). E-mail: fmarton2003@yahoo.com.br

${ }^{3}$ Mestre em Desenvolvimento Regional e Urbano(UNIFACS). Professor da Universidade do Estado da Bahia (UNEB). E-mail: romilson-moreira@ bol.com.br
}

Recebido em: 17/02/2014

Aceito em: 27/03/2014 


\section{INTRODUÇÃO}

A literatura sobre o impacto dos arranjos institucionais, como as estruturas de negociação salarial sobre o desempenho econômico tem se concentrado nos efeitos sobre o desemprego (CALMFORS, 1993). Conforme Ferrari Filho e Terra (2011), as proposições reformistas de Keynes exigem uma atenção especial ao regime de ajuste de preços e salários para verificar se sua consistência está isenta de pressões inflacionistas em pleno emprego. Nesse sentido, pretende-se com esta pesquisa, sugerir que um certo grau de centralização e de coordenação de ajuste de pagamento seja adequada e pertinente.

Outro aspecto que se deve destacar nessa contextualização é a de que as políticas de aumento da oferta surgem a partir da necessidade de algo que se aproxima de um saldo da conta corrente no exterior a um nível aceitável de desemprego. O crescimento da economia doméstica é, então, definido pelo crescimento da economia mundial.

Algumas linhas de pensamento indicam que o papel das políticas keynesianas não é mais relevante (SANTOS, 2008). Esta pesquisa, com viés popperiano, parte justamente da negação dessa premissa, buscando confirmar a utilidade das políticas keynesianas, com enfoque específico na garantia do pleno emprego. Para isso, adotou-se como metodologia para o presente estudo, a adoção de um levantamento bibliográfico, tendo como resultado final um ensaio teórico, que busca refletir a respeito da temática abordada.

Assim, o desenvolvimento do presente texto busca inicialmente discutir e interpretar as políticas econômicas keynesianas num contexto amplo; em seguida, apresenta evidências teóricas de uma conjuntura mais específica, entendo que as políticas econômicas keynesianas como sinônimo de gestão de demanda fiscal projetada para regular a economia de mercado.

No entanto, ressalta-se que existem gargalos que envolvem a busca do pleno emprego, decorrente da demanda e a oferta. Portanto, a relevância desta pesquisa assenta-se na busca de contribuir com uma discussão teórica voltada para o objetivo basilar das políticas keynesianas: a mitigação dos gargalos na busca do pleno emprego. Portanto, a abordagem deste artigo volta-se à política econômica pós-keynesiana (COSTA NETO, 2000), tendo como objetivo apresentar uma discussão teórica baseada na Administração Política, com foco nas contribuições para a garantia do pleno emprego.

Sendo assim, o presente ensaio teórico sustenta-se em duas perspectivas: (a) explicar o que são as políticas keynesianas e as operações das economias de mercado; e (b) apresentar 
possíveis explicações relacionadas às restrições ao pleno emprego. Além disso, conta com a presente introdução e considerações finais.

\section{O QUE SÃO AS POLÍTICAS KEYNESIANAS? O QUE SÃo OPERAÇÕES DAS ECONOMIAS DE MERCADO?}

O termo "políticas keynesianas" tem sido associado ao conceito de gestão de demanda, sobretudo por pesquisadores que procuram alinhar a economia com a política fiscal.

O conceito defendido por este estudo se difere e não se sustenta na premissa de alinhamento entre política fiscal e economia, pois se discute que a política keynesiana defende a ideia de que o governo usa os déficits orçamentários excedentes com o objetivo de escorar um nível de demanda agregada necessária à geração de altos níveis de emprego, além de, evidentemente, empregar a política monetária para atingir o menor nível possível de taxas de juros. Assim, criando as condições necessárias à expansão da capacidade produtiva com uma maior oferta de emprego.

Apesar do enfoque deste ensaio se centrar sobre as políticas destinadas ao pleno emprego, não se pode omitir dessa discussão conceitual as considerações que envolvem o crescimento da produção e da produtividade, muito embora essas medidas de melhoria de abastecimento possam ser associadas à lei da oferta e da demanda.

Sendo assim, menciona-se dois pressupostos básicos de Keynes para o funcionamento das economias de mercado. O primeiro, uma economia de mercado laissez-faire não costuma gerar pleno emprego, como defendida pelos autores clássicos, pois Keynes nega o princípio da "Lei do Say" e do ajustamento automático da economia capitalista.

O legado do pensamento keynesiano estruturara-se historicamente com a negativa dos fundamentos clássicos da economia. Num contexto de crises pós 1929, o desemprego elevado, acompanhado de grande depressão na atividade econômica, coloca em contradição a crença na mão invisível de Smith. Recentemente, a crise dos subprimes, concentrada com maior força nos EUA, comprovou a necessidade de regulação dos mercados. Em suma, os clássicos, defendem que os governos não devem realizar intervenções econômicas significativas (SHAPIRO, 1996).

O segundo pressuposto de Keynes é que o pleno emprego resulta numa distribuição mais equitativa da renda do mercado, poder e riqueza, sendo uma meta desejável em si mesma, pois promove o aumento da prosperidade geral (ARESTIR, 1992). Nesse sentido, 
Keynes (1936, p. 372) afirmou que "[...] os defeitos fundamentais da sociedade econômica em que vivemos são sua incapacidade de fornecer para o pleno emprego e sua distribuição arbitrária e desigual de riqueza e renda". Portanto, faz-se necessária a regulação articulada dos mercados por meio de forte mecanismos de intervenção estatal. No entanto, essa intervenção deverá ser realizada de forma a comprometer os incentivos da iniciativa privada para o aumento da produção e da produtividade.

Numa pesquisa global desenvolvida pelo Programa das Nações Unidas para o Desenvolvimento, concluiu-se que existe uma correlação positiva entre crescimento econômico e igualdade de renda. Umas das recomendações deste estudo indica a extrema importância da redução da exclusão social e econômica nas formas de pleno emprego e participação mais ativa no mercado de trabalho como forma de combater as desigualdades crescentes na distribuição dos lucros e rendimentos de uma sociedade (OECD, 1996).

Portanto, pode-se concluir que as políticas keynesianas defendem a intervenção do Estado para se alcançar o pleno emprego e a promoção do bem estar social (welfare state), opondo-se aos pressupostos defendidos pelo liberalismo, como forma de garantir um padrão mínimo de vida à população. Percebe-se, ainda, que uma das ideias fundamentais de Keynes é de que o Estado deve fomentar a demanda de forma a movimentar a economia (DAVIDSON, 1994).

No que se refere às operações das economias de mercado, pode-se refletir que numa economia monetária descentralizada não existe um mecanismo espontâneo no mercado garantidor da demanda agregada indispensável à obtenção da oferta agregada de pleno emprego. Dessa forma, a demanda agregada imprópria pode impossibilitar a concretização do pleno emprego. A problemática do alinhamento entre a demanda agregada e da oferta agregada potencial pode ser vista como uma implicação fatal de uma economia monetária descentralizada, independente da adoção de paliativos como as políticas e arranjos institucionais (DAVIDSON, 1994).

Esse argumento basilar de Keynes sobre a relevância da demanda agregada sobre a influência da oferta agregada é entusiasmado pela perspectiva do longo prazo da demanda agregada. Entende-se, portanto, que a oferta efetiva de trabalho é sensivelmente afetada pela demanda de trabalho, pois altos níveis de demanda por emprego atraem pessoas para a força de trabalho, em contrapartida, níveis baixos de demanda levam as pessoas para fora do mercado. A política keynesiana de pleno emprego defende, então, que não é só relações como 
utilização da capacidade e taxa de desemprego que são influenciados pela demanda agregada, mas também a economia de escala.

A partir da perspectiva do desemprego, compreendido como uma "imperfeição" do cenário econômico surge a importância da retirada dessas "imperfeições" como um dos mais importantes objetivos da política econômica governamental. Sendo assim, aponta-se como um exemplo característico das imperfeições econômicas, o resultado do estudo de Andrade e Amaral (2012), para quem a nova estrutura produtiva mundial contempla o desemprego e a precarização do trabalho, apresentando-se com baixo dinamismo da produção e recorrentes variações no nível de atividade econômica, recaindo com maior força sobre a população mais jovem.

Considerando a Europa como o continente berço do welfare state, menciona-se a Eurostat (2012), publicada em abril de 2012, que compara a taxa de desemprego para o período de um ano. Sendo assim, informa que o desemprego regrediu em oito EstadosMembros da União Europeia, aumentou em dezoito e ficou estabilizada na Romênia. As maiores quedas foram registradas na Lituânia (de 17,5\% para 14,3\% entre os quartos trimestres de 2010 e 2011), Letônia (de 17,0\% para 14,6\% entre os quartos trimestres de 2010 e 2011) e Estônia (de 13,9\% para 11,7\% entre os quartos trimestres de 2010 e 2011). Os maiores aumentos do desemprego foram registados na Grécia (de 14,3\% para 21,0\% entre dezembro de 2010 e dezembro de 2011), Espanha (de 20,6\% para 23,6\%) e Chipre (de 6,7\% para 9,7\%). Já as menores taxas de desemprego foram registradas na Áustria (4.2\%), na Holanda (4.9\%), em Luxemburgo (5.2\%) e Alemanha (5.7\%).

Pelo visto, o aumento da taxa de desemprego tem sido mais forte nos países com sistema econômico mais frágil, merecendo atenção especial o índice de desemprego na Grécia, Espanha e Chipre, sendo resultado do mal funcionamento da economia, principalmente considerando que dezoito $(66,67 \%)$ dos 27 Estados-Membros da União Europeia tiveram aumento da taxa de desemprego.

Diante do exposto, apresenta-se oportunamente as três vertentes que explicam o funcionamento das economias de mercado: a concorrência, a localização geográfica e desenvolvimento econômico e os gargalos para o atingimento do pleno emprego.

Com relação à concorrência, defende-se que num processo de competitividade, existem relevantes forças políticas, econômicas e sociais que originam e reforçam as diferenças e disparidades entre indivíduos ou nações. Resulta na aplicação da noção de que o 
sucesso gera mais sucesso. Uma região economicamente bem-sucedida gera lucros que comportam mais investimentos, já o desemprego e os baixos salários são dois atributos de regiões relativamente menos prósperas, sendo que o pleno emprego nas regiões mais prósperas promove desemprego nas regiões menos prósperas (COWLING, 1990).

No que se refere à localização geográfica, entende-se que as regiões relativamente atrasadas experimentam não somente os níveis mais baixos de renda per capita, mas também afrontam altos níveis de desemprego e de austeras restrições em sua capacidade de crescer. A noção de vantagem competitiva contém um forte elemento de contribuição cumulativa para o sucesso em um determinado período de tempo, que promove um excedente que pode ser utilizado para construir o sucesso em períodos seguintes, contudo, vale ressaltar que a disponibilidade de excedente não garante que ele será empregado para construir o sucesso futuro, pois muitos fatores podem provocar imperfeições na competição perfeita, que tem como principal função fazer funcionar a economia de mercado.

Por fim, existem diversas limitações para se atingir o pleno emprego, em que o reconhecimento desses gargalos resulta numa consignação de que as forças de mercado não são suficientes por si só para gerar pleno emprego (FERRARI FILHO; TERRA, 2011).

Diante do exposto, no capítulo seguinte, serão tratados os detalhes que podem promover as restrições ao pleno emprego

\section{RESTRIÇÕES AO PLENO EMPREGO}

Nesta pesquisa, destacam-se seis prováveis restrições à realização do pleno emprego: falta da utilização da capacidade, restrição à inflação, financiamento dos déficits orçamentários, restrição da balança comercial, restrição da demanda agregada e restrição da alta produtividade. Ressalta-se, no entanto, que cada restrição pode acontecer sem associação com outra, em seu devido tempo ou contexto.

Para Keynes, o componente capaz de aumentar o nível de emprego numa economia capitalista estava ancorado no aumento dos gastos em consumo e em investimento. Em outras palavras, quem determina o volume da produção e, portanto, o volume do emprego, é a demanda efetiva que não é apenas a demanda efetivamente realizada, mas ainda, o que se espera que seja gasto em consumo e investimento. 


\subsection{FALTA DA UTILIZAÇÃO DA CAPACIDADE}

Os fatores que estimulam o investimento privado e, por consequência, o estoque de capital (como utilização da capacidade e rentabilidade do investimento) são diferentes dos fatores que determinam o tamanho da força de trabalho. A partir desse contexto, pode-se afirmar que não existem razões específicas para ponderar que o capital social será adequado para a prestação de pleno emprego. A conjuntura econômica apresenta oportunidades limitadas, especialmente no curto prazo, no que diz respeito à substituição entre trabalho e capital social. Seria esperar que um período total de crescimento lento e prolongado de investimento fique abaixo do que seria necessário para sustentar o pleno emprego.

Para Keynes (1936), o sistema capitalista não garante o pleno emprego, pois ele só mantém a produção de bens e serviços se houver otimismo do mercado, ou seja, em momentos de pessimismo decide-se pela redução da capacidade produtiva prejudicando o atingimento do pleno emprego.

\subsection{RESTRIÇÃO À INFLAÇÃO}

Outro ponto pertinente a destacar é a influência que a inflação representa para a concretização do pleno emprego. Inicialmente, pode-se considerar a relevância da taxa de "não aceleração" da inflação do desemprego, ou seja, uma barreira de inflação para o pleno emprego. Segundo, as estimativas de alteração da taxa de "não aceleração" da inflação do desemprego ao longo do tempo, tendem a mover-se em linha com a experiência real de desemprego e são sensíveis à especificação do modelo econométrico e métodos de estimativa. Por fim, pode haver pressões inflacionárias associadas ao pleno emprego. Nessas circunstâncias, a inflação deve ser a expressão de algumas outras limitações subjacentes, e, provavelmente, deva ser mais apropriadamente designada em outro contexto (STIGLITZ, 1997).

Para Argitis e Michopoulou (2011) a ampliação do poder dos mercados financeiros e a adoção de políticas fiscais e deflacionárias constituem-se em obstáculos ao pleno emprego e à promoção de um crescimento igualitário. Porém, apontam o pleno emprego como um elemento necessário ao atingimento do crescimento e da equidade social. Diante disso, propõem a adoção do programa de Empregador de Última Instância (Employer of Last Resort 
- ELR), que resulta na contratação pelo governo dos trabalhadores aptos e desejosos de trabalhar por meio de um salário pré-estabelecido.

Os autores, no entanto, mencionam que a adoção do ELR não solucionará todos os problemas inerentes à pobreza e ao capitalismo. No entanto, num ambiente de financeirização dos mercados, apontam três razões para a estratégia: 1) é possível agir no sentido de conduzir ao pleno emprego; 2) é provável não resultar em inflação; e 3) garante o apoio dos contribuintes ao programa, diante da promoção de benefícios públicos como segurança, ruas limpas, cuidado infantil, atendimento aos idosos, dentre outros.

Pelo exposto, esse ponto de discussão dá abertura para um longo e profundo debate, mas que neste artigo, restringe-se a apontar somente estes contextos. Assim, sugere-se uma pesquisa específica sobre a manutenção do pleno emprego e a influência da inflação na economia, por exemplo.

\subsection{FINANCIAMENTO DOS DÉFICITS ORÇAMENTÁRIOS}

Quando a renda do pleno emprego gera um excesso de poupança em relação ao investimento em produção de bens e serviços, quais são os limites para o uso dos déficits orçamentários para preencher esta lacuna? Existem duas possibilidades (não excludentes, mas sim relacionadas) do que o governo execute um déficit orçamentário para sustentar o pleno emprego: (a) déficits orçamentários (que são insustentáveis) e (b) utilização do poder de financiamento dos mercados financeiros.

Os mercados financeiros são muitas vezes vistos como limitadores da adoção de políticas fiscais, seja por meio das taxas de juros, o que limita o governo em adquirir empréstimos, seja por reações negativas do mercado de câmbio, o que faz o valor da moeda despencar. Os mercados financeiros representam um tipo diferente de restrição na busca de políticas fiscais quando ocorre, por exemplo, o "efeito manada" e o estouro de bolhas no mercado mobiliário. $\mathrm{O}$ ponto mais importante para se compreender nesta discussão é que os mercados financeiros podem ser uma fonte de instabilidade, que pode ser transmitida para outros setores da economia e os participantes desse mercado que têm a capacidade de influenciar a política econômica. A base de sustentação das políticas keynesiana defende que se deve conter o poder e a influência dos mercados financeiros (ARESTIS; SAWYER, 1997).

Com base em Kaboub (2013), as recessões têm sido utilizadas pelos neoliberais para manter uma agenda favorável, pois os lucros caem fazendo surgir uma pressão das 
corporações sobre os sindicatos, recaindo na redução de salários, cortes de benefício; e sobre os governos, na busca da redução de impostos, aumento de incentivos fiscais e obtenção de contratos públicos lucrativos. Com o aumento do déficit orçamentário, as ameaças também ocorrem, bem como no momento da recuperação fiscal, em que a redução dos impostos e a redução das garantias da seguridade social tornam-se de caráter permanente e irreversível.

Ainda segundo Kaboub (2013), não existe uma solução que contrarie a posição neoliberal. No entanto, menciona que é possível aumentar a justiça social com a geração de pleno emprego que contribua para o crescimento do PIB. Sendo assim, defende que países com soberania financeira, emissores de moeda, como os Estados Unidos, Canadá, Reino Unido, Austrália e Japão, não podem se limitar aos níveis de déficits e dívidas nacionais que possuem, já que suas dívidas são limitadas em suas próprias moedas.

\subsection{RESTRIÇÃO DA BALANÇA COMERCIAL}

A restrição da balança comercial tem um nível e dimensão de crescimento. O resultado de balança comercial é a diferença entre as importações e exportações, e se negativa, a diferença deve ser coberta por empréstimos externos, e, portanto, cria obrigações para os pagamentos de juros futuros. Uma balança comercial que persiste em apresentar déficit comercial envolve um déficit em conta corrente crescente como os pagamentos de juros sobre estes empréstimos. No entanto, desde que o crescimento da economia nacional supere a taxa de juros sobre os empréstimos externos, existirá uma tendência de estabilização da renda. Portanto, pode-se perceber a importância que a balança comercial tem na geração e manutenção do pleno emprego.

Evidentemente que essa restrição não impacta todos as nações, justamente por que se em alguns países houve déficit, logo, pelo menos, outro apresentará superávit comercial (SAWYER, 1995).

\subsection{RESTRIÇÃO DA DEMANDA AGREGADA}

As taxas de juros são determinadas mais por análise de liquidez do que as forças de produtividade e da economia instalada. Especificamente, as taxas de juros não equiparam a poupança e o investimento em um mesmo patamar. A aplicação de uma poupança é 
determinada por um conjunto de fatores completamente diferente dos que influenciam um planejado e não há conjuntura que reforce a igualdade de renda de pleno emprego.

Não existe a mínima possibilidade dentro de uma economia de mercado de trabalho, a segurança de que o nível de demanda agregada é ajustado com o pleno emprego do trabalho e do capital social. Na melhor das hipóteses, pode ocorrer momentos provisórios, em que a demanda por investimentos é mais alta do que a demanda por poupança. No entanto, quando a poupança tende a ultrapassar os investimentos em produção de bens e serviços, as forças de trazer o investimento e a poupança numa mesma linha de pleno emprego são fracas ou até mesmo inexistentes (DAVIDSON, 1994).

\subsection{RESTRIÇÃO DA ALTA PRODUTIVIDADE}

$\mathrm{O}$ alcance de elevados coeficientes de produtividade exige uma intensidade de trabalho adequada e um relevante compromisso por parte dos trabalhadores, assim como o fornecimento de um aparelhamento de capital satisfatório, treinamento e habilitações. Em muitas economias de mercado, o desemprego, ou até mesmo o risco de desemprego, serve como um organismo extraordinário para a imposição de um nível elevado de intensidade de trabalho (KALECKI, 1943). O nível de desemprego não é uma escolha das empresas, mas sim, o que fornece o contexto em que as empresas operam. Cabe ressaltar que essa restrição não defende que o desemprego é indispensável para a garantia do esforço de trabalho. Na realidade, o desemprego aumenta o medo e promove a desmoralização e as economias de mercado diferentes recorreram a mecanismos que não o desemprego (SINGH, 1994).

\section{CONSIDERAÇÕES FINAIS}

Considerando o exposto no presente ensaio teórico, pode-se destacar que os argumentos keynesianos da necessidade da intervenção do governo na economia, para atingir e manter o pleno emprego se justificam contemporaneamente. $O$ incremento da representatividade dos sindicatos e trabalhadores em pleno emprego, juntamente com as pressões inflacionárias resultantes, devem ser destacadas nestas considerações finais. $\mathrm{O}$ consenso social sobre a distribuição de renda, juntamente com a fixação de preços e salários, são estruturas que instigam a baixa inflação. Políticas para melhorar o lado da oferta da economia podem se tornar necessárias para suavizar a problemática que envolve o pleno 
emprego. Mesmo com demanda suficiente, o pleno emprego ainda pode ser difícil, se não impossível, para manter, se existe uma oferta insuficiente ou desequilibrada.

Pode-se destacar, ainda, que a contribuição deste ensaio se sustenta no sentido de oferecer mais um referencial teórico sobre a temática do pleno emprego para pesquisadores da Administração Política e da Economia. Sugere-se como proposta para pesquisas futuras, um tratamento empírico sobre essas discussões, com o objetivo de analisar em algum contexto real a aplicabilidade das políticas keynesianas na geração e manutenção do pleno emprego.

Evidentemente que a inovação tecnológica, promotora do aumento de produção e da produtividade sem o respectivo aumento de postos de trabalho, também resulta num desafio ao alcance do pleno emprego defendido por Keynes. Assim, acredita-se que o desenvolvimento de pesquisas que relacione a política do pleno emprego nos moldes keynesianos com a inovação também sejam oportunas.

\section{REFERÊNCIAS}

ARESTIR, P. The Post-Keynesian Approuach to Economics: An Alternative Analysis of Economic Theory and Policy. Aldershot: Edward Elgar Publishing Company, 1992.

Macmillan Press, 1997.

; SAWYER, M. (Ed.) The Relevance of Keynesian Policies Today. Londres:

ARGITIS, Georgios; Michopoulou, Stella. Are Full Employment and Social Cohesion Possible Under Financialization? For Soc Econ, v. 40, pp. 139-155, 2011.

CALMFORS, L. Centralisation of wage bargaining and macroeconomic performance: a survey. OECD Economics Departament Working Papers, 1993.

COSTA NETO, A. A. C. Os Limites à Intervenção Monetária Estatal: As Contribuições Marxistas e Pós-Keynesianas e a Experiência Brasileira no Período 1964/90. Tese (Doutorado em Administração). Universidade Federal da Bahia, Salvador, 2000.

COWLING, K. The strategic approach to economic and industrial policy. In Cowling and Sudgen (Ed.). A New Economic Policy for Britain. Manchester: MUP, 1990.

DAVIDSON, P. Post Keynesian Macroeconomic Theory: A foundation of Successful Economic Policies for the Twenty-first Century. Aldershort: Edward Elgar, 1994.

EUROSTAT. Eurostat newsreleaseeuroindicators. 52/2012, 02 april 2012. Disponível em: http://epp.eurostat.ec.europa.eu/cache/ITY_PUBLIC/3-02042012-AP/EN/3-02042012-APEN.PDF Acesso em: 16 jan. 2014. 
FERRARI FILHO, F.; TERRA, F. As disfunções do Capitalismo na visão de Keynes e suas proposições reformistas. Revista Econômica Contemporânea, v. 15, n. 2, 2011.

KALECKI, M. Political aspects of full employment. Political Quartely, v. 14, n. 4, 1943.

KEYNES, J. M. The General Theory of Employment, Interest and Money. London: Macmillan, 1936.

KABOUB, Fadhel. The Fiscal Cliff Mythology and the Full Employment Alternative: An Affordable and Productive Plan. Review of Radical Political Economics, v. 45, n. 3, pp. 305-314, 2013.

OECD. Employment Outlook, n. 14, London: HMSO, 1996.

SANTOS, R. S. Keynes e a proposta de Administração Política do Capitalismo. Revista Brasileira de Administração Política (REBAP), v. 1, 2008.

SAWYER, M. The intellectual and Institucional requirements for full employment. In Davidson and Kregel (Ed.) The political Economy of Full Employment: Conservatism, Corporatism, Institutional Change. Aldershot: Edward Elgar, 1995.

SHAPIRO, N. Imperfect Competition and Keynes'. In Harcourt and Riach (Ed.) The Second Edition of the General Theory. Londres: Routledge, 1996.

SINGH, A. Institutional requirements for full employment in advanced economies. International Labour Review, v. 134, 1994.

STIGLITZ, J. Reflections on the natural rate hypothesis. Journal of Economic Perspectives, v. 11, n.3, 1997. 